\title{
A PREFORMULATION STUDY ON INTERACTIONS BETWEEN DOXORUBICIN HYDROCHLORIDE AND BOVINE SERUM ALBUMIN
}

\author{
K. C. AJITHKUMAR, K. PRAMOD* \\ College of Pharmaceutical Sciences, Govt. Medical College, Kozhikode 673008, Kerala, India \\ Email: pramodkphd@yahoo.com
}

Received: 09 Sep 2017, Revised and Accepted: 10 Oct 2017

\section{ABSTRACT}

Objective: The objective was to study the effect of concentrations of doxorubicin hydrochloride (Dox) and bovine serum albumin (BSA) in a sample on fluorescence intensity, UV absorbance, refractive index and optical rotation.

Methods: A circumscribed central composite statistical design with 2 factors, 5 levels, and 13 runs was selected for the study. According to that influence of both in interaction was measured by fluorescence intensity, UV absorbance, refractive index and optical rotation and were analyzed by the design expert software.

Results: It was observed that concentration of BSA alone was significantly affecting the fluorescence intensity and optical rotation of samples. Dox alone was having a significant effect on UV absorbance at $280 \mathrm{~nm}$. In the case of a refractive index, both Dox and BSA were having a significant effect. But the effect of BSA was much pronounced than that of Dox on refractive index.

Conclusion: Interaction studies between BSA and Dox would be beneficial as they are commonly used in combination with tumor-targeted delivery. The interaction was observed that in a linear model for a wide range of concentration of both. So it will be useful to determine the interaction of unknown concentration.

Keywords: Fluorescence intensity, UV absorbance, Optical rotation, Refractive index

(C) 2017 The Authors. Published by Innovare Academic Sciences Pvt Ltd. This is an open access article under the CC BY license (http://creativecommons.org/licenses/by/4.0/) DOI: http://dx.doi.org/10.22159/ijap.2017v9i6.22470

\section{INTRODUCTION}

Drug-excipient interaction studies are very important $[1,2]$. There are many drug-excipient interaction studies reported for conventional dosage forms such as tablets and capsules [3]. But nowadays a good number of reports are there on bovine serum albumin (BSA) and doxorubicin hydrochloride (Dox) for tumor targeted delivery [4-7]. In this scenario, it would be interesting to carry out a study on interactions between Dox and BSA.

In this study, the effect of concentrations of Dox and BSA in a sample of fluorescence intensity, UV absorbance, refractive index and optical rotation was evaluated. There four dependent factors or responses are seldom considered in any reported work on BSA and Dox. Statistical evaluation using the design of experiments is a simple and powerful tool to determine the effect of independent formulation factors on various dependent factors [8]. Here we checked the effect of concentrations of Dox and BSA on some dependent factors such as fluorescence intensity, UV absorbance, optical rotation and refractive index.

\section{MATERIALS AND METHODS}

\section{Materials}

Doxorubicin hydrochloride (Dox) and bovine serum albumin (BSA) was obtained from Sigma-Aldrich Co. (MO, USA). Reagent grade I water (Millipore, Molsheim, France) was used for the study.

\section{Evaluation of the effect of concentrations of Dox and BSA}

A circumscribed central composite statistical design with 2 factors, 5 levels, and 13 runs was selected for the study using Design-Expert 8.0.0.6 software (State-Ease Inc, Minneapolis, USA). This design is suitable for exploring quadratic response surfaces and constructing second-order polynomial models. The independent and dependent variables are listed in table 1.

Table 1: Variables and their constraints for central composite design

\begin{tabular}{|c|c|c|c|c|c|c|}
\hline \multicolumn{7}{|c|}{ Independent factors } \\
\hline \multirow[t]{2}{*}{ Factor code } & \multirow[t]{2}{*}{ Factor } & \multicolumn{5}{|l|}{ Levels } \\
\hline & & -1.414 & -1 & $\mathbf{0}$ & +1 & +1.414 \\
\hline A & Dox concentration, (mM) & 0.15 & 0.3 & 0.65 & 1.0 & 1.14 \\
\hline B & BSA concentration, (mM) & 0.01 & 0.05 & 0.15 & 0.25 & 0.29 \\
\hline \multicolumn{7}{|c|}{ Dependent factors (Responses) } \\
\hline Response code & Response & & & & & \\
\hline R1 & Fluorescence intensity (mAU) & & & & & \\
\hline $\mathrm{R} 2$ & UV absorbance at $280 \mathrm{~nm}$ & & & & & \\
\hline R3 & Refractive index & & & & & \\
\hline $\mathrm{R} 4$ & Optical rotation $\left({ }^{\circ}\right)$ & & & & & \\
\hline
\end{tabular}

The coded and actual values for the selected central composite experimental design matrix were as given in table 2. BSA and Dox solutions were prepared and stored in dark (protected from light) at $4{ }^{\circ} \mathrm{C}$.

The samples were prepared by mixing and subjected to evaluation.

\section{Fluorescence intensity}

The fluorescence intensity of the samples was determined at an excitation wavelength of $280 \mathrm{~nm}$ and an emission wavelength of 347 using a spectrofluorophotometer (Shimadzu RF-5301PC spectro-fluoro-photometer, Shimadzu Scientific Instruments Inc., Marylan, U. S. A). 
Table 2: The central composite experimental design matrix

\begin{tabular}{lllll}
\hline Run & Coded values & & Actual values \\
\cline { 2 - 4 } & Dox concentration & BSA concentration & Dox concentration (mM) & BSA concentration (mM) \\
\hline 1 & -1 & -1 & 0.30 & 0.05 \\
2 & 1 & -1 & 1.00 & 0.05 \\
3 & -1 & 1 & 0.30 & 0.25 \\
4 & 1 & 1 & 1.00 & 0.25 \\
5 & -1.414 & 0 & 0.15 & 0.15 \\
6 & 1.414 & 0 & 1.14 & 0.15 \\
7 & 0 & -1.414 & 0.65 & 0.01 \\
8 & 0 & 1.414 & 0.65 & 0.29 \\
9 & 0 & 0 & 0.65 & 0.15 \\
10 & 0 & 0 & 0.65 & 0.15 \\
11 & 0 & 0 & 0.65 & 0.15 \\
12 & 0 & 0 & 0.65 & 0.15 \\
13 & 0 & 0 & 0.65 & 0.15 \\
\hline
\end{tabular}

Dox: Doxorubicin hydrochloride, BSA: Bovine serum albumin

\section{UV-Vis spectrophotometry}

The UV absorbance of sample at $280 \mathrm{~nm}$ was determined using a UVvisible spectrophotometer (Agilent Cary 100, Agilent Technologies, Santa Clara, CA, United States) equipped with Cary WinUV software.

\section{Refractive index}

Refractive index was determined by Refractometer (Abbemat 350, Anton Paar India Pvt. Ltd., Haryana, India) at589 $\mathrm{nm}$ and $20.0^{\circ} \mathrm{C}$ temperature.

\section{Optical rotation by polarimetry}

Optical rotation of samples was determined by Saccharimeter (Sac-i, Atago India Instruments Pvt Ltd., Mumbai, India) with the modified validated procedure using $1 \mathrm{~cm}$ path length quartz cuvette at 589 $\mathrm{nm}$ (D-line of sodium lamp at visible wavelength).

\section{RESULTS AND DISCUSSION}

\section{Evaluation of the effect of concentrations of Dox and BSA}

The influence of doxorubicin hydrochloride and BSA concentration with the analytical parameters were determined by evaluating the all the 13 batches proposed by the experimental design.

Table 3 displays the results obtained for various experimental runs suggested by the software. The contour and response surface plots are shown in fig. 1.

Table 3: Results obtained for various experimental runs

\begin{tabular}{lllll}
\hline Run & Responses & & & \\
\cline { 2 - 5 } & Fluorescence intensity & UV absorbance & Refractive index \\
\hline 1 & 200.84 & 1.3331 & -0.009 & 0.019 \\
2 & 189.939 & 1.3331 & -0.019 & 0.107 \\
3 & 1003.238 & 1.3341 & -0.046 & 0.035 \\
4 & 995.874 & 1.3342 & -0.044 & 0.113 \\
5 & 697.932 & 1.3336 & -0.016 & 0.022 \\
6 & 631.287 & 1.3336 & 0 & 0.131 \\
7 & 43.009 & 1.3328 & -0.045 & 0.076 \\
8 & 1127.806 & 1.3343 & -0.02 & 0.071 \\
9 & 633.12 & 1.3336 & -0.02 & 0.093 \\
10 & 574.659 & 1.3336 & -0.013 & 0.074 \\
11 & 598.399 & 1.3336 & -0.013 & 0.092 \\
12 & 670.098 & 1.3336 & -0.022 \\
13 & 593.322 & 1.3336 & 0.077 \\
\hline
\end{tabular}

A

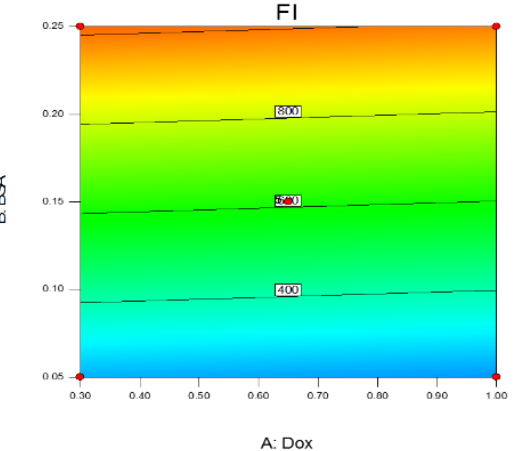

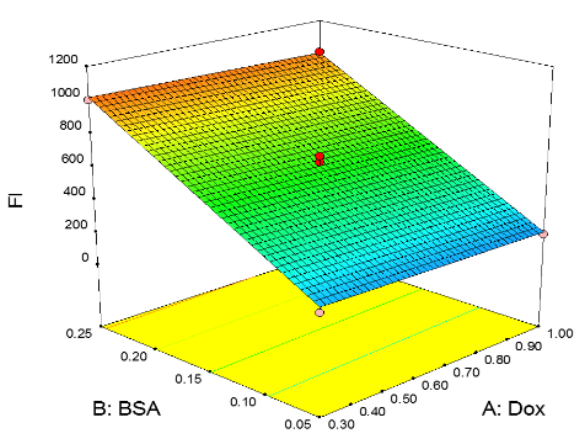




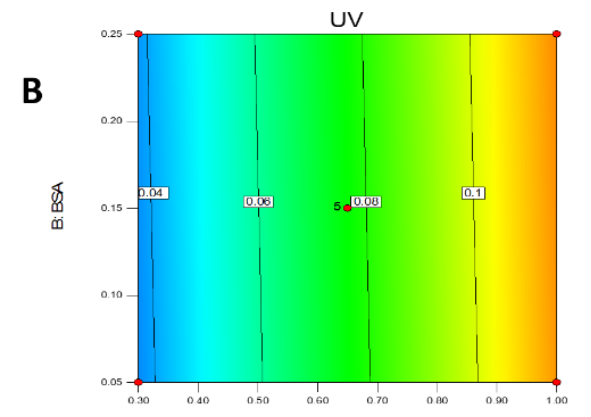

A: Dox
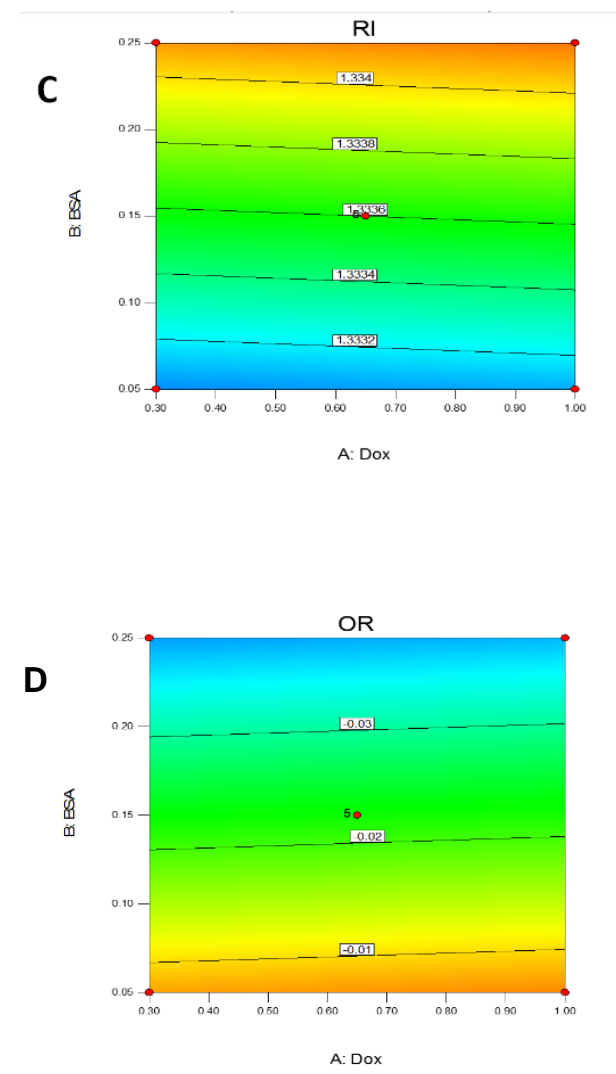

Fig. 1: Contour and response surface plots of (A) Fluorescent intensity, (B) UV absorbance, (C) Refractive index and (D) Optical rotation

\section{Effect on fluorescence intensity}

The Analysis of variance (ANOVA) table for the response surface linear model is given in table 4 . The model was found to be significant whereas lack of fit was found to be not significant. The predicted R-square value of 0.9784 was comparable with the adjusted R-Square value of 0.9857 . Adequate precision value of 59.804 was acceptable. Here the effect of BSA alone was significant. This was evident from the contour and response surface plots obtained for fluorescence intensity (fig. 1A). In the contour plot it can be seen that the iso-value curves are almost parallel to the $\mathrm{x}$-axis of Dox and perpendicular to the y-axis of BSA. The results implied that Dox almost have no effect on the fluorescence intensity whereas BSA has much effect on fluorescence intensity. A similar observation is also seen in the response surface plot. The surface level does not
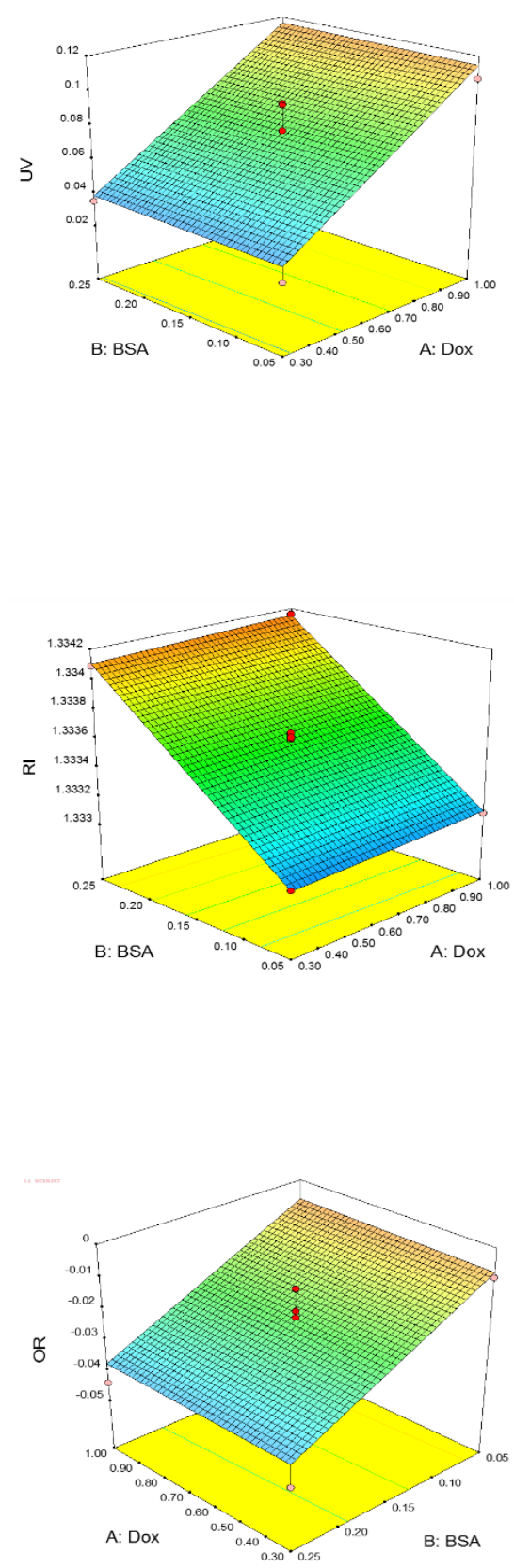

change much on change on changing Dox but increased significantly on increasing BSA. Thus increased BSA concentration caused increased fluorescence intensity.

\section{Effect on UV absorbance at $280 \mathrm{~nm}$}

The ANOVA table for the response surface linear model is given in table 5 . The model was found to be significant whereas lack of fit was found to be not significant.

The predicted R-square value of 0.9176 was comparable with the adjusted R-Square value of 0.9325 . Adequate precision value of 26.967 was acceptable. Here the effect of Dox alone was significant. This was evident from the contour and response surface plots obtained for UV absorbance at $280 \mathrm{~nm}$ (fig. 1B). In 
the contour plot, it can be seen that the iso-value curves are almost perpendicular to the $\mathrm{x}$-axis of Dox and parallel to $\mathrm{y}$-axis of BSA. The results implied that BSA almost have no effect on the UV absorbance whereas Dox has much effect on UV absorbance.
A similar observation is also seen in the response surface plot. The surface level does not change much on change on changing BSA but increased significantly on increasing Dox. Thus increased Dox concentration caused increased UV absorbance at $280 \mathrm{~nm}$.

Table 4: ANOVA for response surface linear model for fluorescence intensity

\begin{tabular}{|c|c|c|c|c|c|}
\hline Source & Sum of squares & df & Mean square & F Value & p-value prob $>F$ \\
\hline Model & $1.236 \mathrm{E}+006$ & 2 & $6.180 \mathrm{E}+005$ & 413.21 & $<0.0001$ \\
\hline$A-D o x$ & 1582.46 & 1 & 1582.46 & 1.06 & 0.3279 \\
\hline$B-B S A$ & $1.234 E+006$ & 1 & $1.234 E+006$ & 825.36 & $<0.0001$ \\
\hline Residual & 14955.71 & 10 & 1495.57 & --- & --- \\
\hline Lack of Fit & 9224.50 & 6 & 1537.42 & 1.07 & 0.4956 \\
\hline Pure Error & 5731.21 & 4 & 1432.80 & --- & --- \\
\hline Cor Total & $1.251 \mathrm{E}+006$ & 12 & --- & --- & --- \\
\hline
\end{tabular}

Table 5: ANOVA for response surface linear model for UV absorbance

\begin{tabular}{|c|c|c|c|c|c|}
\hline Source & Sum of squares & df & Mean square & F value & p-value prob $>F$ \\
\hline Model & 0.012 & 2 & $6.053 \mathrm{E}-003$ & 83.94 & $<0.0001$ \\
\hline$A-D o x$ & 0.012 & 1 & 0.012 & 167.82 & $<0.0001$ \\
\hline$B-B S A$ & $4.394 E-006$ & 1 & $4.394 E-006$ & 0.061 & 0.8100 \\
\hline Residual & $7.211 \mathrm{E}-004$ & 10 & 7.211E-005 & --- & --- \\
\hline Lack of Fit & $3.759 E-004$ & 6 & $6.265 E-005$ & 0.73 & 0.6549 \\
\hline Pure Error & $3.452 E-004$ & 4 & 8.630E-005 & --- & --- \\
\hline Cor Total & 0.013 & 12 & --- & --- & --- \\
\hline
\end{tabular}

\section{Effect on refractive index}

The ANOVA table for the response surface linear model is given in table 6. The model was found to be significant whereas lack of fit was found to be not significant. The predicted R-square value of 0.9981 was comparable with the adjusted R-Square value of 0.9985 . Adequate precision value of 185.242 was acceptable. Here the effect both Dox and BSA was significant. But the effect of BSA was much pronounced than that of Dox. This was evident from the contour and response surface plots obtained for refractive index (fig. 1C). In the contour plot, it can be seen that the iso-value curves are more or less perpendicular to $y$-axis of BSA thus implying its significant effect on the refractive index. A slight inclination of iso-value curves are noted towards the higher values of Dox concentration along the $\mathrm{x}$-axis. This implied that increased Dox concentration causes a slight, but statistically significant, increase in refractive index. But an increased in BSA concentration caused drastic increase in refractive index. A similar observation is also seen in the response surface plot. The surface level drastically changed with BSA concentration whereas slightly with Dox concentration.

Table 6: ANOVA for response surface linear model for refractive index

\begin{tabular}{|c|c|c|c|c|c|}
\hline Source & Sum of squares & df & Mean square & F value & p-value prob $>F$ \\
\hline Model & $2.239 \mathrm{E}-006$ & 2 & $1.119 \mathrm{E}-006$ & 3968.16 & $<0.0001$ \\
\hline$A-D o x$ & $4.950 E-009$ & 1 & $4.950 E-009$ & 17.55 & 0.0019 \\
\hline$B-B S A$ & $2.234 E-006$ & 1 & $2.234 E-006$ & 7918.77 & $<0.0001$ \\
\hline Residual & 2.821E-009 & 10 & $2.821 \mathrm{E}-010$ & --- & -- \\
\hline Lack of Fit & $1.341 E-009$ & 6 & $2.234 E-010$ & 0.60 & 0.7236 \\
\hline Pure Error & $1.480 E-009$ & 4 & $3.700 E-010$ & -- & -- \\
\hline Cor Total & $2.241 \mathrm{E}-006$ & 12 & --- & --- & -- \\
\hline
\end{tabular}

\section{Effect on optical rotation}

The ANOVA table for the response surface linear model is given in table 7. The model was found to be significant whereas lack of fit was found to be not significant. The predicted R-square value of 0.6437 was comparable with the adjusted R-Square value of 0.7626 . Adequate precision value of 13.247 was acceptable. Here the effect of BSA alone was significant. This was evident from the contour and response surface plots obtained for optical rotation (fig. 1D). In the contour plot, it can be seen that the iso-value curves are almost parallel to $\mathrm{x}$-axis of Dox and perpendicular to y-axis of BSA. The results implied that Dox almost have no effect on the optical rotation whereas BSA has much effect on optical rotation. A similar observation is also seen in the response surface plot. The surface level does not change much on change on changing Dox but increased significantly on increasing BSA. Thus increased BSA concentration caused increased optical rotation.

Table 7: ANOVA for response surface linear model for optical rotation

\begin{tabular}{|c|c|c|c|c|c|}
\hline Source & Sum of squares & df & Mean square & F value & p-value prob $>F$ \\
\hline Model & $1.976 \mathrm{E}-003$ & 2 & $9.880 \mathrm{E}-004$ & 20.28 & 0.0003 \\
\hline$A-D o x$ & $2.794 E-006$ & 1 & $2.794 E-006$ & 0.057 & 0.8156 \\
\hline$B-B S A$ & $1.973 E-003$ & 1 & $1.973 E-003$ & 40.49 & $<0.0001$ \\
\hline Residual & 4.873E-004 & 10 & 4.873E-005 & --- & --- \\
\hline Lack of Fit & $4.141 E-004$ & 6 & $6.901 E-005$ & 3.77 & 0.1098 \\
\hline Pure Error & 7.320E-005 & 4 & $1.830 E-005$ & --- & --- \\
\hline Cor Total & $2.463 \mathrm{E}-003$ & 12 & --- & --- & --- \\
\hline
\end{tabular}




\section{CONCLUSION}

The effect of concentrations of Dox and BSA on some dependent factors such as fluorescence intensity, UV absorbance, optical rotation and refractive index were studied. A circumscribed central composite statistical design with 2 factors, 5 levels, and 13 runs was selected for the study. From the results, it was observed that concentration of BSA alone was significantly affecting the fluorescence intensity and optical rotation. Dox alone was having a significant effect on UV absorbance at $280 \mathrm{~nm}$. In the case of a refractive index, both Dox and BSA were having a significant effect. But the effect of BSA was much pronounced than that of Dox on refractive index.

\section{ACKNOWLEDGEMENT}

K. C. Ajithkumar gratefully acknowledges Kerala State Council for Science, Technology and Environment (KSCSTE), Thiruvananthapuram, India, for sanctioning student project (No. 14/SPS 57/2016/ KSCSTE, Dated 02.04.2016).

\section{CONFLICT OF INTERESTS}

\section{Declared none}

\section{REFERENCES}

1. Ceresole R, Han YK, Rosasco MA, Orelli LR, Segall A. Drugexcipient compatibility studies in binary mixtures of avobenzone. J Cosmet Sci 2013;64:317-28.
2. Gomathi T, Govindarajan C, Rose HR MH, Sudha PN, Imran PK, Venkatesan J, et al. Studies on drug-polymer interaction, in vitro release and cytotoxicity from chitosan particles excipient. Int J Pharm 2014;468:214-22.

3. Ebrahimi A, Saffari M, Dehghani F, Langrish T. Incorporation of acetaminophen as an active pharmaceutical ingredient into porous lactose. Int J Pharm 2016;499:217-27.

4. Qu X, Yang C, Zhang J, Ding N, Lu Y, Huang L, et al. In vitro evaluation of a folate-bovine serum albumin-doxorubicin conjugate. J Drug Target 2010;18:351-61.

5. Huang $\mathrm{H}$, Yang DP, Liu M, Wang X, Zhang Z, Zhou G, et al. $\mathrm{pH}$ sensitive Au-BSA-DOX-FA nanocomposites for combined CT imaging and targeted drug delivery. Int $\mathrm{J}$ Nanomed 2017;12:2829-43.

6. Liu G, Tsai HI, Zeng X, Zuo Y, Tao W, Han J, et al. Phosphorylcholine-based stealthy nanocapsules enabling tumor microenvironment-responsive doxorubicin release for tumor suppression. Theranostics 2017;7:1192-203.

7. Aji Alex MR, Nehate C, Veeranarayanan S, Kumar DS, Kulshreshtha R, Koul V. Self assembled dual responsive micelles stabilized with protein for co-delivery of drug and si RNA in cancer therapy. Biomaterials 2017;133:94-106.

8. Fayed MH, Abdel-Rahman SI, Alanazi FK, Ahmed MO, Tawfeek $\mathrm{HM}$, Al-Shdefat RI. New gentle-wing high-shear granulator: impact of processing variables on granules and tablets characteristics of high-drug loading formulation using design of experiment approach. Drug Dev Ind Pharm 2017;43:1584-600. 